NASA Technical Memorandum 105421

$p^{6}$

\title{
Advanced Communication Technology Satellite (ACTS) Multibeam Antenna Technology Verification Experiments
}

Roberto J. Acosta and Jeffrey M. Larko

Lewis Research Center

Cleveland, Ohio

and

Alan R. Lagin

Analex Corporation

Brook Park, Ohio

Prepared for the

1992 AP-S International Symposium

sponsored by the Institute of Electrical and Electronic Engineering

Chicago, Illinois, July 18-25, 1992 



\title{
ADVANCED COMMUNICATION TECHNOLOGY SATELLITE (ACTS) MULTIBEAM ANTENNA TECHNOLOGY VERIFICATION EXPERIMENTS
}

\author{
Roberto J. Acosta and Jeffrey M. Larko \\ National Aeronautics and Space Administration \\ Lewis Research Center \\ Cleveland, Ohio 44135 \\ Alan R. Lagin \\ Analex Corporation \\ Brook Park, Ohio 44142
}

\begin{abstract}
The Advanced Communication Technology Satellite (ACTS) is a key to reaching NASA's goal of developing high-risk, advanced communications technology using multiple frequency bands to support the nation's future communication needs. Using the multiple, dynamic hopping spot beams and advanced on board switching and processing systems, ACTS will open a new era in communications satellite technology. One of the key technologies to be validated as part of the ACTS program is the multibeam antenna with rapidly reconfigurable hopping and fixed spot beam to serve users equipped with small-aperture terminals within the coverage areas. The proposed antenna technology experiments are designed to evaluate in-orbit ACTS multibeam antenna performance (radiation pattern, gain, cross pol levels, etc.)
\end{abstract}

\section{Introduction-Experiments Description and Goals}

The ACTS multibeam antenna technology verification experiments are divided in two general categories, direct and indirect performance evaluations. The direct antenna performance evaluation consist of in-orbit antenna pattern measurements. The indirect antenna performance evaluations consist of inferring antenna performance by simulating the spacecraft thermal/RF environment (Ref.1), measurement of the reflector surface and structures temperature and continuously monitoring the downlink $\mathrm{C} / \mathrm{N}$ power ratios.

The measurements of in-orbit antenna patterns of the ACTS spacecraft will characterize (Ref.2-3) the antenna system performance (gain, pointing, sidelobe level,etc.). This measurements will also be used to verify the thermal/RF analysis computer codes. The direct identification of individual causes for antenna performance degradation from thermal effects may not be possible to determine from the measured antenna patterns. These effects of thermal distortions on the performance of ACTS antenna system may be indirectly assessed from the measured reflector surface and structures temperatures. This data can be used in conjunction with thermal/RF analysis program for estimating ACTS antenna performance.

Also by continuously monitoring the downlink $\mathrm{C} / \mathrm{N}$ power ratios at the NASA Lewis ground station it is possible to determine and correlate the changes in received power to changes in antenna performance due to thermal effects. spacecraft drift, autotrack drift, etc. 


\section{In-Orbit RF Antenna Pattern Measurements}

Multiple antenna far-field pattern (co pol and cross pol) cuts can be obtained by maneuvering (Ref. 4) the ACTS spacecraft (north-south and westeast) using the momentum wheel mechanism on board the spacecraft (Figure 1). This is in principle similar to performing a routine far-field antenna test.

\section{Thermal/Structure/RF Analys is Computer Program}

NASA Lewis Research Center has developed-a computer algorithm (Ref. 5) that combines thermal structural characteristics with RF antenna performance (Figure 2). The RF analys is code utilizes physical optics to simulate the ACTS multibeam antenna system. The structural and thermal program utilizes TRASYS, NASTRAN and SYNDA computer programs to analyze the thermal deflection on the antenna system.

\section{Reflector Surface Temperature Measurements}

The ACTS spacecraft includes 20 thermal (Figure 3) sensors on the main reflector and 3 sensors on the sub-reflector. The actual point temperatures on the reflector surface are measured and available on a telemetry channel. A two dimensional polynomial surface interpolation is used to generate sufficient temperature points for estimating the antenna performance.

\section{C/N Power Ratio Measurements}

The overall antenna distortions impact on antenna performance (structural deformations, polarization impurity, etc.) can be indirectly assessed by using a minimum of one ground station. This measurement can be done without affecting normal operation of the station. The receive power is recorded with respect to time and correlated to the spacecraft thermal cycles.

\section{Preliminary Results and Discussions Thenal Distortion Analys is}

The worst case thermal cycle of the ACTS spacecraft are simulated by the thermal/structure/RF analys is program and the corresponding antenna performance estimated. Specifically the conditions associated to maximum cold and maximum gradient were analyzed. The ACTS antenna system is simulated without taking into account the structures holding the reflectors to the spacecraft. Figure $4 a$ shows the ideal case far-field antenna pattern, figure $4 b$ shows the maximum cold case far-field antenna pattern and figure $4 c$ shows the maximum gradient case far-field antenna pattern. All simulations are for the spot beam located on Cleveland and operating at a carrier frequency of $19.7 \mathrm{GHz}$. The changes in antenna performance for all cases are minimum, for example gain degradation with respect to ideal was less that $0.5 \mathrm{~dB}$. Changes in sidelobe level were not appreciable, some differences occur in the $-20 \mathrm{db}$ sidelobe level or lower.

More work is underway to include the effects on antenna performance due to 
structure deformations. It is expected that this type off effect will cause severe pointing error and its prediction is of extreme importance.

\section{References}

1. Acosta, R. J.;Active Feed Array Compensation for Reflector Antenna Surface Distortions. NASA TM-100826, 1988.

2. Hughes, C.D and Gough,R.A; In-Orbit Measurements of OTS Payload performance, American Institute of Aeronautics and Astronautics, Inc., 1980.

3. Brian, D.J.: In-Orbit Antenna Pattern Measurements on The European Orbital Test Satellite. International Conference on Antennas and Propagation, London, England, November 28-30, 1978, Proceeding, Part 1.

4. Kozu, Toshiaki;Murakami, Hidetoshi; Arai, Katsuyohi and Mochizyki,Ryo; Measurements of K-Band Antenna Patterns. IEEE Transactions on Broadcasting, Vol. BC-28, No. 4, December 1982.

5. Sharp, G.R.;Acosta, R.J.;Bobinsky, E.A. and Shaker, F.J.;A Conceptual System Design for Antenna Thermal and Dynamic Distortion Compensation Using a Phased Array Feed. Second NASA/DOD Control/Structures Interac tion Technology Conference, Colorado Spring, CO, November 17-19, 1987. 


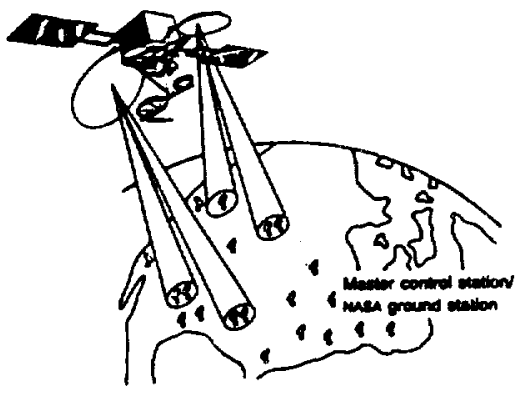

Figure 1. In-Orbit Antenna Pattern Measurements.

THERMAL OISTORTION PERFORMAMCE AHALYSIS PHOGRAM

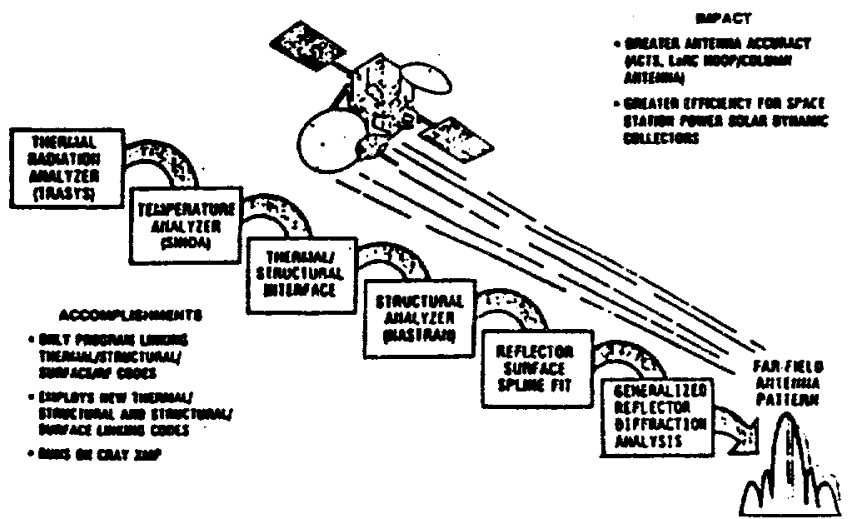

Figure 2, Thermal/Structural/RF Computer Progran 8 lock D1agran

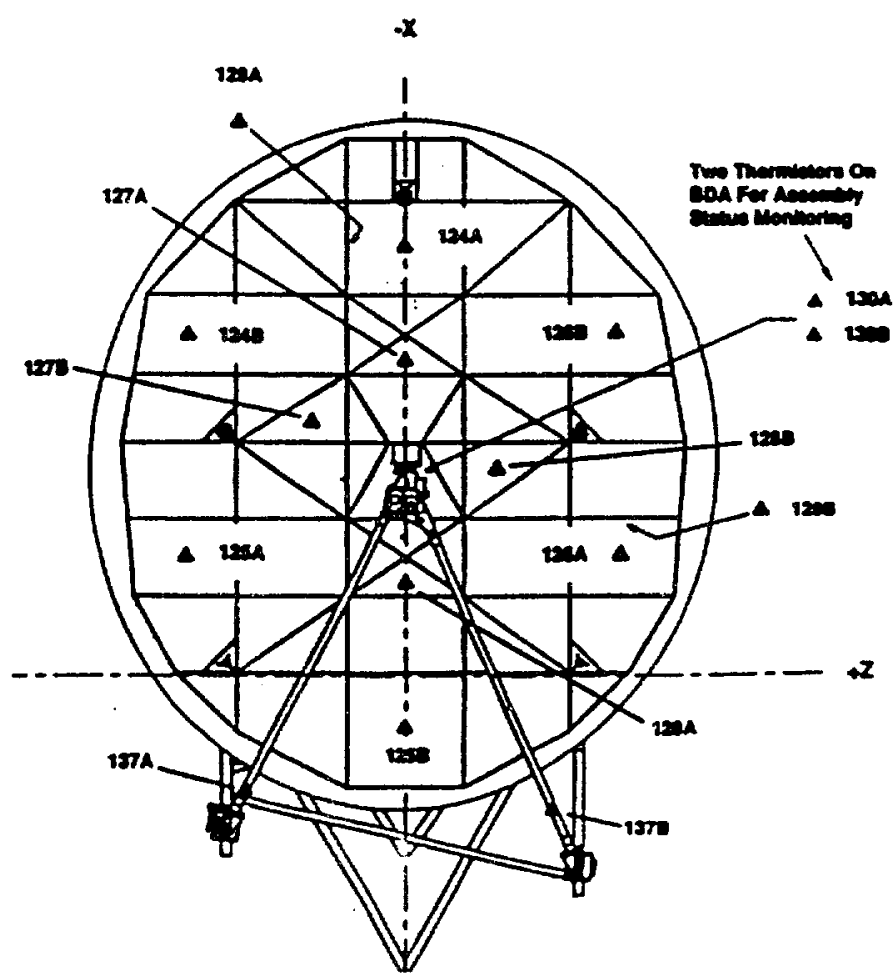

Figure 3, Reflector Surface Temperature Probes.

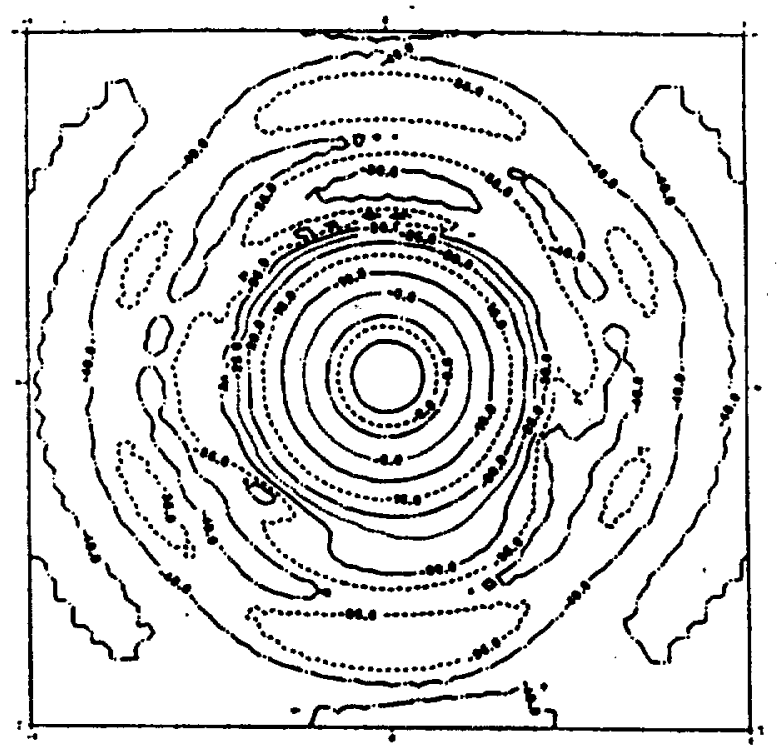

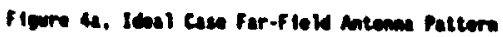

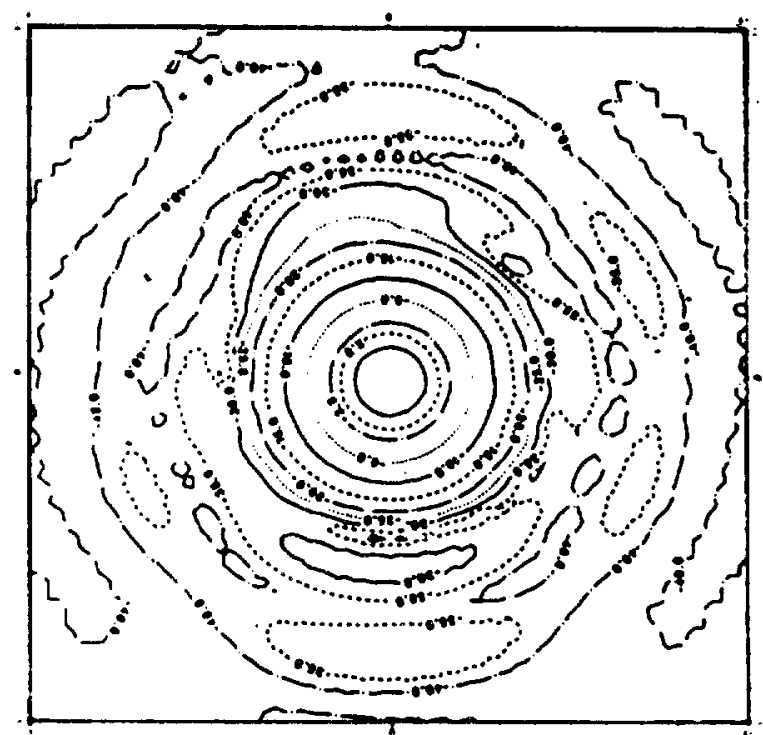

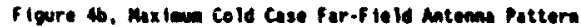

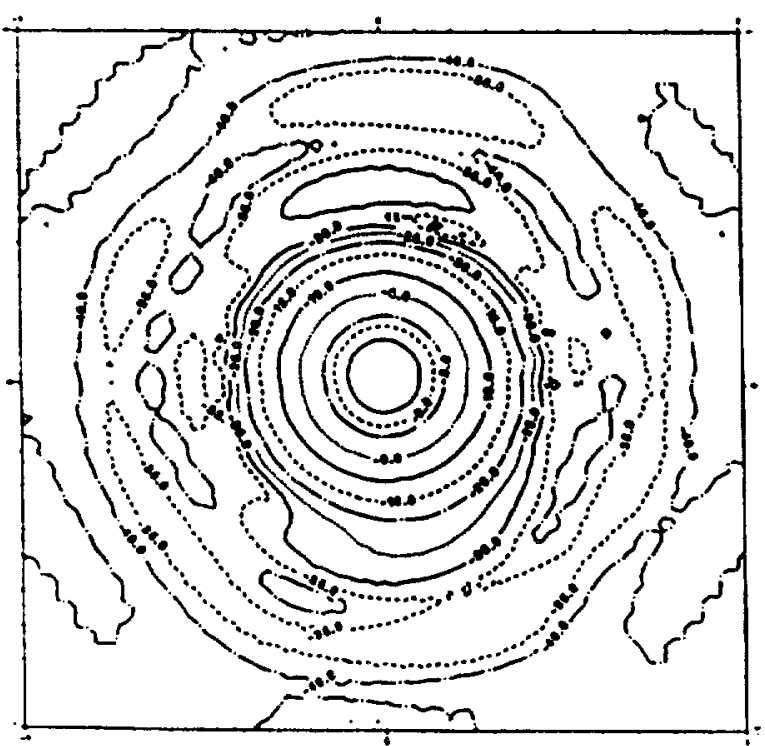

Figure 4c, Mexime Gradiont cose for-field Antema pettern 


\begin{tabular}{|c|c|c|c|}
\hline \multicolumn{3}{|c|}{ REPORT DOCUMENTATION PAGE } & $\begin{array}{l}\text { Form Approved } \\
\text { OMB No. } 0704-0188\end{array}$ \\
\hline \multicolumn{4}{|c|}{ 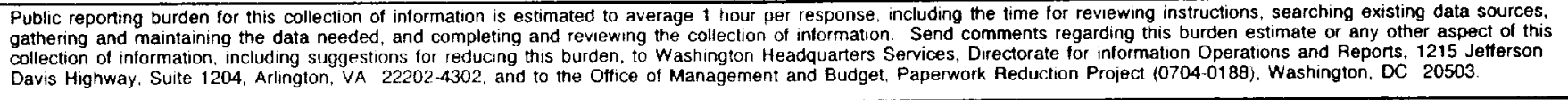 } \\
\hline 1. AGENCY USE ONLY (Leave blank) & $\begin{array}{r}\text { 2. REPORT DATE } \\
1992\end{array}$ & \multicolumn{2}{|c|}{ 3. REPORT TYPE AND DATES COVERED } \\
\hline \multicolumn{3}{|c|}{$\begin{array}{l}\text { 4. TITLE AND SUBTITLE } \\
\text { Advanced Communication Technology Satellite (ACTS) Multibeam } \\
\text { Antenna Technology Verification Experiments }\end{array}$} & 5. FUNDING NUMBERS \\
\hline \multicolumn{3}{|c|}{$\begin{array}{l}\text { 6. AUTHOR(S) } \\
\text { Roberto J. Acosta, Jeffrey M. Larko, and Alan R. Lagin }\end{array}$} & WU $-679-40-00$ \\
\hline \multicolumn{3}{|c|}{$\begin{array}{l}\text { 7. PERFORMING ORGANIZATION NAME(S) AND ADDRESS(ES) } \\
\text { National Aeronautics and Space Administration } \\
\text { Lewis Research Center } \\
\text { Cleveland, Ohio } 44135-3191\end{array}$} & $E-6836$ \\
\hline \multicolumn{3}{|c|}{$\begin{array}{l}\text { 9. SPONSORING/MONITORING AGENCY NAMES(S) AND ADDRESS(ES) } \\
\text { National Aeronautics and Space Administration } \\
\text { Washington, D.C. } 20546-0001\end{array}$} & NASA TM- 105421 \\
\hline \multicolumn{4}{|c|}{$\begin{array}{l}\text { 11. SUPPLEMENTARY NOTES } \\
\text { Prepared for the } 1992 \text { AP-S International Symposium sponsored by the Institute of Electrical and Electronic Engineering, } \\
\text { Chicago, Illinois, July 18-25, 1992. Roberto J. Acosta and Jeffrey M. Larko, NASA Lewis Research Center; Alan R. } \\
\text { Lagin, } 3001 \text { Aerospace Parkway, Brook Park, Ohio } 44142 \text {. Responsible person, Roberto J. Acosta, (216) 433-6640. }\end{array}$} \\
\hline \multicolumn{2}{|c|}{$\begin{array}{l}\text { 12a. DISTRIBUTION/AVAILABILITY STATEMENT } \\
\text { Unclassified - Unlimited } \\
\text { Subject Category } 32\end{array}$} & & 12b. DISTRIBUTION CODE \\
\hline \multicolumn{4}{|c|}{$\begin{array}{l}\text { 13. ABSTRACT (Maximum 200 words) } \\
\text { The Advanced Communication Technology Satellite (ACTS) is a key to reaching NASA's goal of developing high-risk, } \\
\text { advanced communications technology using multiple frequency bands to support the nation's future communication } \\
\text { needs. Using the multiple, dynamic hopping spot beams and advanced on board switching and processing systems, } \\
\text { ACTS will open a new era in communications satellite technology. One of the key technologies to be validated as part } \\
\text { of the ACTS program is the multibeam antenna with rapidly reconfigurable hopping and fixed spot beam to serve users } \\
\text { equipped with small-aperture terminals within the coverage areas. The proposed antenna technology experiments are } \\
\text { designed to evaluate in-orbit ACTS multibeam antenna performance (radiation pattern, gain, cross pol levels, etc.) }\end{array}$} \\
\hline \multirow{2}{*}{\multicolumn{3}{|c|}{$\begin{array}{l}\text { 14. SUBJECT TERMS } \\
\text { Reflector antennas; Antenna measurements; Multibeam antenna }\end{array}$}} & $\begin{array}{c}\text { 15. NUMBER OF PAGES } \\
6\end{array}$ \\
\hline & & & $\begin{array}{r}\text { 16. PAICE CODE } \\
\text { A02 }\end{array}$ \\
\hline $\begin{array}{l}\text { 17. SECURITY CLASSIFICATION } \\
\text { OF REPOHT } \\
\text { Unclassified }\end{array}$ & $\begin{array}{l}\text { 18. SECURITY CLASSIFICATION } \\
\text { OF THIS PAGE } \\
\text { Unclassified }\end{array}$ & $\begin{array}{l}\text { 19. SECURTY CLASSIFICATION } \\
\text { OF ABSTRACT } \\
\text { Unclassified }\end{array}$ & 20. LIMITATION OF ABSTRACT \\
\hline
\end{tabular}


